Journal of Social Sciences 7 (2): 141-145, 2011

ISSN 1549-3652

(C) 2010 Science Publications

\title{
Does Humor Matter? From Organization Management Perspective
}

\author{
${ }^{1}$ Kai-Ping Huang and ${ }^{2}$ Wen-Ching Kuo \\ ${ }^{1}$ School of Management, University of Technology, Sydney, Australia \\ PO Box 123, Broadway NSW 2007, Australia \\ ${ }^{2}$ Admission Centre, TransWorld University, Taiwan \\ 1221, Jen-Nang Rd., Chia-Tong Village, Douliou City, Yunlin, Taiwan 640
}

\begin{abstract}
Problem statement: This study is to provide an overview discussion on the issue of humor management of within organizations. Although there are limits to which a work environment can be relaxed through humor or any other device, bonding through humor can be an important device within an organization whereby unity and common purpose are realized. Types of humor in the workplace can include puns, slapstick, jokes and anecdotes and teasing. Humor is also an important device for dealing with change. Approach: The literature review and arguments were conducted to identify the function, importance and influence of humor within organizations. Results: By observing humor and by being sensitive to its implications, rather than dismissing it simply as frivolity, managers can implement changes based on their interpretations of workplace humor. Negatively, humor can be an important device for protecting self-image and one's social peers within an organization; where managers observe such socialization, they can move to improve staff relations. Spontaneous humor is also a useful training device, for evaluating how well new ideas have been communicated. Humor then can be a spur to initiative and to spontaneous responses. Where a manager wants to engage in pleasantries with employees then, it seems that industrially democratic humor is an important component of such interaction. Humor can be an important factor in industrial democracy and increased productivity. Conclusion: Humor can be an important device for building a tram spirit and for forming a cohesive unit, unanimously concerned with its own survival and profitability.
\end{abstract}

Key words: Organization management, observing humor, senior management, industrial democracy, work environment, literature review, organization whereby unity, effective organize, maximizing profit, repressive environment, spontaneous humor

\section{INTRODUCTION}

Humor can be very important to the cultivation of an environment in which workers perform their functions efficiently. It can lead to higher levels of productivity than a repressive environment where interaction is very controlled and disciplined. Of course, there are limits to which a work environment can be relaxed through humor or any other device. Work environments are primarily task oriented and their raison d'etre is to realize high levels of output, usually with a view to maximizing profit (Ismail et al., 2009). But employees whose relations are very constrained or who feel overly monitored can shirk or feel intimidated in such a way that productivity falls. On the other hand, joking has to be monitored for the damaging effect it can have on work relations. But often managers do not use humor as a tool for change or see it as a threatening. A number of writers (Crawford, 1994; Romero and Cruthirds, 2006) see humor as under-rated by managers for its relative impact, though there is justification for treating it seriously.

\section{MATERIALS AND METHODS}

Based to literature review, the study is to provide several constructs in relation to humor and organizations and they are as follows.

Humor as communication: Humor is common in many communication forms and relevant to the study of organizations. Humor can be regarded as an important tool in many ways, as a serious mechanism for building sound social relations in the workplace; it may be that the successful firms do in fact have environments where

Corresponding author: Kai-Ping Huang, School of Management, University of Technology, Sydney, Australia, PO Box 123, Broadway NSW 2007, Australia 


\section{J. Social Sci., 7 (2): 141-145, 2011}

humor is pivotal to socialization and task related interaction. It can be seen to facilitate communication, to build relationships, to reduce stress, to provide perspective and deflate self-importance or undue emphasis on a particular project or policy and to promote concentration and motivation (Sultanoff, 1993; Martin et al., 2003). Also, humor in communication creates an open atmosphere by awakening positive emotions that enhance listening, understanding and acceptance of messages (Greatbatch and Clark, 2002). Where it is disallowed or used negatively though, communication can be impeded, relationships between peers or between managers and staff can be undermined, human resources can experience damaging stress levels, perspectives can be clouded and concentration and motivation can be eroded.

Bonding: Bonding through humor can be an important device within an organization whereby unity and common purpose are realized. Conversely, joking can result in disintegration if it is allowed to go unchecked where it is inappropriate. In either case it can be a powerful social instrument, rather than merely a pastime. Through bonding, workers realize a common set of values that can be beneficial to the firm and its output. Absenteeism and shirking can be avoided as a workforce is cemented together (Barelds and Barelds-Dijkstra, 2010)

That is, the "bonding aspect of humor may have a significant impact on workplace productivity and employee levels of satisfaction" (Vinton, 1989). Workers who can socialize effectively in the workplace are less likely to avoid it. Also, because they want the approval of their workmates in an environment where they feel accepted, joking is not likely to become a substitute for effort, but even a spur to it. Several types of humor can be used to motivate peers and juniors or subordinates more effectively than reprimands or cautions or threats of insecurity. Types of humor in the workplace can include puns, slapstick, jokes and anecdotes and teasing (Vinton, 1989).

Teasing is often a coaxing device used both by peers and superiors to enhance efficiency. Other types of humor can be used in ways that could be explained as offensive or inappropriate to employees outside the organization and may be a means whereby a team builds a barrier to the rest of the community. This barrier can however cause the team or work group to coalesce around a set of unifying values, as occurs in a culture. Humor can be a means whereby these values become accessible, rather than mystified or removed.

Change: Humor is also an important device for dealing with change. In the past 20-30 years, social values have changed considerably together with work environments effected by technological change. A generation ago, it was not unacceptable to exclude persons from work on the basis of gender, race, age or religion. Now, at least in western countries and a few other developed countries, this is no longer the case. But persons in these countries still see some ambiguity in these changes, in comparison to what they see as the fairly recent past (Cruthirds, 2006; Brett et al., 2006). Often, such humor may seem inappropriate or insensitive, but it can be an important device in the process of adjustment and change.

That is not to say that organizations can be allowed to follow different standards or values in terms of community values, or that they can be permitted to allow for different standards in terms of vilification of minorities or less powerful groups. Rather, by observing humor and by being sensitive to its implications, rather than dismissing it simply as frivolity, managers can implement changes based on their interpretations of workplace humor. For example, jokes that are used for purposes of sexual harassment under the guise of worker camaraderie can be damaging to workplace relations and be symptomatic of the need for change. Such humor need not only be between a superior male and a subordinate female; male subordinates may use humor to unsettle and sexually harass a female manager, so that these jokes become a weapon in industrial. Management needs be aware of worker attitudes to changing opportunities in the workplace so that its newly developed staff can function effectively. Such attitudes by a workforce need be monitored in relation to race religion, sexual preference and any other area where equal opportunity concerns apply. Such concerns are not only important because of equity either, but also in order to bring about an environment where a manager, or any other human resources, can realize potential.

Further, "When environments are complex and changing, conditions are ripe for the experience of contradiction, incongruity, incoherence and the recognition of paradox and ambiguity within organizations” (Hatch and Ehrlich, 1993). Again, as staffs come to incorporate computers, fax machines, electronic passwords and email into their ordinary work lives, they may often feel intimidated and their self-esteem may be threatened. Humor can be an important device for protecting self-image and one's social peers within an organization. Where spontaneous humor is used, in an organizational context, however, it is nearly always used in a manner directly relevant to the business concerns of the organization, although this can include human resources related matters (Hatch and Ehrlich, 1993). 


\section{J. Social Sci., 7 (2): 141-145, 2011}

Spontaneous humor: Spontaneous humor, too, can be more important than a set joke or response and be a means of revealing pent up feeling in a relatively safe way, even it may seem to challenge or rebuke the hierarchy in the organization, it can be a soft way of voicing a grievance while indicating a willingness to remain on good terms. Spontaneous humor then is often rooted in a serious or task-based discussion with an apparent purpose, but it also points up an apparent incongruity or dysfunction in the discourse that is disrupted by the humorous observation, but this humor can serve in a remedial way. Its sensibility is linked to its social context and it forms a discourse over a number of utterances rooted in the organizational history concerned, together with the use of such humor (Hatch and Ehrlich, 1993).

Spontaneous humor is also a useful training device, for evaluating how well new ideas have been communicated. That is humor can be "linked to paradox and ambiguity in such a way as to make it a useful indicator of discourse relevant to interpreting paradox and ambiguity" (Hatch and Ehrlich, 1993), particularly as it relates to the acceptance and digest of change in an organization. For example, in organizations where security devices such as passwords and voiceprints are used, it is apparent to employees that they are not trusted; they can be seen as antipathetic to the organization for which they work. Managers who implement such systems can be seen as untrusting or suspicious. Yet it is important for such managers to cultivate a good work environment where they are not seen as simply custodial; at the same time, it is not going to serve a longer term role if these managers deliberately side against the senior management of which they are seen to be representative. Hence, the manager in such a situation might consciously or unconsciously use spontaneous humor to denigrate the untrusting system, as if making a faux pas, while retaining a link to senior management. Hence, the manager reconciles two roles to some degree retaining or regaining some of the support of his staff through a supposed solecism, while remaining in a managerial role.

Spontaneous humor itself is not paradoxical or ambiguous; rather it is a device for identifying paradox and ambiguity and can be treated as ways for asking for explaining information rather than deliberate attempts at obfuscation. This type of humor then is a means by which employees can communicate a plea for deeper understanding, or whereby different levels of a hierarchy can exculpate themselves from implementations or expectations that are difficult to justify, but which cannot be avoided within a particular level or role of responsibility. Thus, it is important for eliciting information needed for productivity or for forestalling poor industrial relations that could undermine established levels of productivity. So, the spontaneous facade of a remark may merely be a device for communicating information or stances that cannot be otherwise affected. Where humor is disallowed or punished in some way, organizations may in fact be less able to realize solutions to problems because they are not identified, or because easy speculation concerning solutions is disallowed in an informal context. If subjects are treated as being above humorous or spontaneous observation, they may also be seen as too far removed from empirical reality and isolated, inappropriately to some theoretical milieu.

Humor and Leadership: Humor is recognized as an effective tool in, even though many managers may regard humor as undermining their authority, or as beneath their dignity; others may see it as a way in which their authority is eroded because it reduces the distance necessary between them and their staff. In other words, humor could be used to enhance by securing a person's power in hierarchical relationships and reducing social distance between leaders and their followers (Holmes and Marra, 2006; Robinson and Smith-Lovin, 2001; Decker and Rotundo, 2001).

However, even conservative employers such as the United States Revenue Service claim that "employee morale has risen tremendously since the introduction of their humor programme", drawn up by humor consultants (Oliffe et al., 2009; Davis and Kleiner, 1989). Where managers do not use humor there is arguably a sense of alienation and a sense of intrusive governance. Where there is no humor, gloom can become diffusive and organizations are likely to be made up of disloyal human resources looking for other more relaxed leaders. Managers who insist too much on their rank and who are immersed in their position as a leader are unlikely to be effective leaders. If there is no opportunity for spontaneous humor as a channel for constructive criticism, either from workers to management or vice versa, the manager is likely to seem like someone who uses his position to deny others' just opportunity to self-actualize. They may even seem like a king who has usurped his role from a more able monarch and whose main concern as a manager is to be a manager, rather than an effective organizer and optimizer of resources.

Humor then can be a spur to initiative and to spontaneous responses. A manager who denies mirth is also likely to deny experimentation because he will frown on failure. Good humor on the part of the successful manager can include offering easy-going 
latitude for some degree of failure and loss. Most successful innovations that are eventually successful are likely to be marked by a degree of failure. Employees, however, who love their workplace, (Davis and Kleiner, 1989) who feel that they can laugh there, are unlikely to fail; humor will not coincide with negligence or irresponsible acts.

Humor and industrial democracy: Perhaps, managers who do not participate in humor or who prevent it are likely to become the butt of humor even if in secret, so that their prized authority is undermined. Again, if employers engage in humor that reflects a lack of respect for them and which jokes may not be reciprocated are also likely to undermine their status with their employees. It has been observed that "A key finding was that a joke told about an employee is more offensive to others if it is told by the arrogant executive than if it is initiated by any other member of the group" (Duncan and Feisal, 1989). If a manager wants to engage in pleasantries with employees then, it seems that industrially democratic humor is an important component of such interaction. The manager cannot be a stand-up comedian at his employee's expense, as well as a draconian tyrant. Humor is an effective tool for promoting satisfaction and productivity where it is used to lighten mood rather than to create a sardonic environment. At the same time, the environment where the humor occurs will be a specific one, both in terms of an industry and a firm (Norrick and Spitz, 2010).

Further, the application of humor does not have to be intentionally negative or aggressive to certain groups. Background and experience may make a person unable to adapt to the humor used, let alone the message that accompanies it. Therefore, ethnic or cultural humor should always be avoided because it is always at someone's expense.

\section{RESULTS AND DISCUSSION}

Employees and managers have a considerable amount of common ground. They have language and expertise and experience that bind them together in ways that few non-members of the organization could appreciate. The organizational unit can have a unique humor that reflects its culture, just as a family unit can have unique experiences that separate it from the rest of the world. This uniqueness can be a source of great strength and used to create a distinctive productive environment, perhaps enhancing the competitive advantage of the organization. That is, "All humor is situation-specific and it can only be interpreted within the context of the group where it occurs" (Duncan and Feisal, 1989). Some researchers indicated that humor has a positive effect on group cohesiveness, communication, stress reduction, creative thinking, organizational culture and (Canestrari, 2010; Henman, 2001; Greatbatch and Clark, 2002; Abel, 2002).

\section{CONCLUSION}

Humor has been defined as "a specific type of communication that establishes as incongruent relationship or meaning and is presented in a way that causes laughter" (Duncan, 1984). But this does not undermine it as a meaningful of exchange. It is instead a form of exchange that defuses situations where hostility could occur, if used well. Employers who do not use this form of exchange well, or who see it as a waste of time or a form of shirking or of disrespect can be missing an inexpensive opportunity to maximize output and good work relations. Humor can be an important device for building a tram spirit and for forming a cohesive unit, unanimously concerned with its own survival and profitability. Such employees will have a vested interest in demonstrating loyalty to a manager who responds to the good-humored advice and observations of employees and who can use gentle reprimands in the form of jests, rather than harsh rebukes or humiliating criticisms (Jamilah et al., 2010). So humor in the workplace is far from being a joke; it can be pivotal to survival and profitability.

\section{REFERENCES}

Abel, M.H., 2002. Humor, stress and coping strategies. Humor: Int. J. Humor Res., 15, 365-381. DOI: 10.1515/humr.15.4.365

Barelds, D.P.H. and P. Barelds-Dijkstra, 2010. Humor in intimate relationships: Ties among sense of humor, similarity in humor and relationship quality. Humor: Int. J. Humor Res., 23: 447-465. DOI: 10.1515/HUMR.2010.021

Brett, J., K. Behfar and M.C. Kern, 2006. Managing multicultural team. Harvard Bus. Rev., 84: 84-91.

Canestrari, C., 2010. Meta-communicative signals and humorous verbal interchanges: A case study. Humor: Int. J. Humor Res., 23: 327-349. DOI: 10.1515/HUMR.2010.015

Crawford, C.B., 1994. Theory and implications regarding the utilization of strategic humor by leaders. J. Stud., 1: 53-68. DOI: 10.1177/107179199400100406

Cruthirds, K.W., 2006. The impact of humor on mediation. Dispute Resolution J., 61: 32-41.

Davis, A. and B.H. Kleiner, 1989. The value of humor in effective leadership. Leadership Organiz. Dev. J., 10: 1-3. 
Decker, W.H. and D.M. Rotondo, 2001. Relationships among gender, type of humor and perceived leader effectiveness. J. Managerial Issues, 13: 450-465.

Duncan, W.J. and J.P. Feisal, 1989. No laughing matter: patterns of humor in the workplace. Organization. Dynamics, 17: 18-30. DOI: 10.1016/S0090-2616(89)80024-5

Duncan, W.J., 1984. Perceived humor and social network patterns in a sample of task-oriented groups: a reexamination of prior research. Human Relations, 37 895-907. $\quad$ DOI: $10.1177 / 001872678403701102$

Greatbatch, D. and T. Clark, 2002. Laughing with the gurus. Business Strategy Rev., 13: 10-18. DOI: 10.1111/1467-8616.00217

Hatch, M.J. and S.B. Ehrlich, 1993. Spontaneous humor as an indicator of paradox and ambiguity in organizations. Organiz. Stud., 14: 505-526. DOI: 10.1177/017084069301400403

Henman, L.D., 2001. Humor as a coping mechanism: Lessons from POWs. Humor: Int. J. Humor Res., 14: 83-94. DOI: 10.1515/humr.14.1.83

Holmes, J. and M. Marra, 2006. Humor and leadership style. Humor: Int. J. Humor Res., 19: 119-138. DOI: 10.1515/HUMOR.2006.006.

Ismail, A.R., M.R.A. Rani, Z.K.M. Makhbul, K. Sopian and B.M. Deros, 2009. Thermal comfort assessment and optimization of environmental factors by using taguchi method. Am. J. Applied Sci., $\quad$ 6: $\quad 1731-1741 . \quad$ DOI: 10.3844/ajassp.2009.1731.1741

Jamilah, O., M.S.H. Azril, U. Jegak, M. Asiah, A.N. Azman, A.S. Bahaman and K. Thomas, 2010. Can quality of work life affect work performance among government agriculture extension officers? A case from Malaysia. J. Soc. Sci., 6: 64-73. DOI: 10.3844/jssp.2010.64.73
Martin, R.A., P. Puhlik-Doris, G. Larsen, J. Gray and $\mathrm{K}$. Weir, 2003. Individual differences in uses of humor and their relation to psychological wellbeing: Development of the humor styles questionnaire. J. Res. Personality, 37: 48-75.

Norrick, N.R. and A. Spitz, 2010. The interplay of humor and conflict in conversation and scripted humorous performance. Humor. Int. J. Humor Res., 23: 83-111. DOI: 10.1515/HUMR.2010.004

Oliffe, J.L., J. Ogrodniczuk, J.L. Bottorff, T.G. Hislop and M. Halpin, 2009. Connecting humor, health and masculinities at prostate cancer support groups. Psycho-Oncology, 18: 916-926. DOI: 10.1002/pon.1415

Robinson, D.T. and L. Smith-Lovin, 2001. Getting a laugh: Gender, status and humor in task discussions. Soc. Forces, 80: 123-158.

Romero, E.J. and K.W. Cruthirds, 2006. The use of humor in the workplace. Academy Manag. Perspectives, 20: 58-69.

Sultanoff, S.M., 1993. Taking humor seriously in the workplace. Management and HR Related Articles. http://mbakim.blogspot.com/2004/10/takinghumor-seriously-in-workplace.html

Vinton, K.L., 1989. Humor in the workplace it is more than telling jokes. Small Group Behav., 20: 151-166. DOI: $10.1177 / 104649648902000202$ 